\title{
Broad Faculty Participation in Course-Level Evaluation of Student Outcomes Supporting Continuous Improvement of an Undergraduate Engineering Program
}

\author{
Randall D. Manteufel \\ The University of Texas at San Antonio \\ Amir Karimi \\ The University of Texas at San Antonio
}

\begin{abstract}
This paper describes a strategy of requiring all undergraduate engineering courses provide some quantitative assessment of student outcomes (SO) which is used in the overall continuous improvement process for the program. A wide range of learning activities are documented in the process and with more faculty participation being engaged in program accreditation. Except for senior design, courses, all courses have no more than two SO to limit the assessment workload on faculty and increase the quality of the data from each course. Pre-semester workshops help faculty plan learning activities so data collection is manageable and not concentrated at the end of the semester. Best practice activities are shared to encourage faculty to think beyond the use of the final exam or design project to assess SOs in their courses.
\end{abstract}

Keywords: student outcome, abet, continuous improvement, accreditation

\section{INTRODUCTION}

Many engineering programs place a heavy reliance on a few senior-level courses to assess student outcomes (SO) which are used in the overall continuous improvement process for the program. It can be a challenge to get broad faculty participation in the collection and analysis of SO data expected for program accreditation (Bern et. al., 2005). Some have proposed reducing faculty participation to a single faculty member responsible for gathering the SO data in only two courses while all other faculty review the data for the continuous improvement process (Miller 2016). It appears to be more widely accepted to seek broad faculty participation in the accreditation process yet the participation needs to not overly burden individual faculty. Having a SO assessment plan with SO mapped to individual courses is important, especially when faculty are provided templates and guidelines to reduce the assessment workload (Wear et. al., 2012). Generic rubrics have been tailored to ABET so faculty can efficiently adopt and administer them in their course (Pejcinovic, 2020). The rubrics are aligned with ABET program evaluator checklists so evidence can be efficiently prepared and then found by the evaluator during site visit (Barr, 2013). The streamlined collection, assessment and presentation of data promotes faculty ownership of the assessment process without overly burdening the teaching commitment of faculty (Mak \& Sundaram, 2016). It is important to have a balanced and consistent assessment of all SO over multiple courses and multiple instructors 
(Manteufel \& Karimi, 2016). Structuring faculty oversight committee for each SO has been reported to further engage faculty and enhance alignment of program data with ABET expectations (Peridier, 2020). This paper proposes all required engineering courses collect and assess SO to ensure broad faculty participation. Data is collected and analyzed for no more than two SO per course to reduce faculty workload. Pre-semester workshops are provided with examples of rubrics and assessment tools to further streamline the process to target what the ABET evaluator will be looking for during their visit.

In 2017 the Engineering Accreditation Commission (EAC) of ABET modified criterion for SO reducing the number from 11 to 7 , and changing the designation for letters a-k to numbers 1-7 (ABET, 2021). The SO are described in the ABET self-study report for Criterion 3, 4 and 5. The new changes began during the 2019-2020 ABET evaluation cycle (Karimi \& Manteufel, 2020). In many engineering programs, the SO are primarily evaluated in Senior Design course(s), which in many programs is a two-semester course sequence. Some programs focus on a handful of courses (often 10 or less) to collect and analyze SO data from the program. The collection and analysis of course-level data is not dictated by ABET yet there is an understanding that the faculty teaching courses in the program are knowledgeable of the goals for program accreditation and are actively involved in the programs continuous improvement process, which is a requirement for accreditation. In some cases, ABET reviewers have asked basic questions about the accreditation process to a wide range of faculty, especially new Assistant Professors, who have taught core engineering courses. These courses have connections between course objectives, course learning outcomes, and the ABET student outcomes. These courses may not culminate in the highest level of student attainment, but they often contribute foundationally to the attainment of student outcomes that are expected by the time of graduation. The skills, knowledge and behaviors that students acquire are throughout the engineering program, with introduction to communication skills and engineering ethics as early as the Freshman year, typically included in an introductory engineering design/graphics course.

It is understandable that some faculty become disconnected with the ABET continuous improvement process, especially where there is little or weak connection between the course they teach and the collection and analysis of data used to assess SO. Faculty are often helping students develop as engineers, which is a process that is not reserved for the senior design courses. Faculty can contribute to the ABET continuous improvement cycle where in most cases they need to document what they currently do in a course or they may need to modify assignments to more clearly collect and analyze SO related activities where students are gaining skills and knowledge. In order to broaden participation in the ABET accreditation process, a conscious decision was made by the department faculty to collect and analyze no more than two SO for each required undergraduate course.

\section{Student Outcomes}

ABET has developed and issued the SO and has provided detailed guidance on interpretation of each SO. For this paper, the SO are stated here, and a single word in each is highlighted to stress the main area of each SO. For example, SO3 is "communication" and SO4 is "ethical".

- SO1 an ability to identify, formulate, and solve complex engineering problems by applying principles of engineering, science, and mathematics

- SO2 an ability to apply engineering design to produce solutions that meet specified needs with consideration of public health, safety, and welfare, as well as global, cultural, social, environmental, and economic factors

- $\mathrm{SO} 3$ an ability to communicate effectively with a range of audiences

- SO4 an ability to recognize ethical and professional responsibilities in engineering situations and make informed judgments, which must consider the impact of engineering solutions in global, economic, environmental, and societal contexts

- SO5 an ability to function effectively on a team whose members together provide leadership, create a collaborative and inclusive environment, establish goals, plan tasks, and meet objectives 
- SO6 an ability to develop and conduct appropriate experimentation, analyze and interpret data, and use engineering judgment to draw conclusions

- SO7 an ability to acquire and apply new knowledge as needed, using appropriate learning strategies

\section{DISTRIBUTION OF SO}

Initially faculty self-selected the SO for the course they teach. For the 2016 accreditation cycle ABET used the a-k SO identification and faculty designated the SO as being either primary or secondary for the course. Table 1 shows the distribution of SO for all of the required engineering courses in the mechanical engineering program. There were many courses covering SO a and e, while only a few cover other SO. In discussion with faculty, many commented that the courses emphasized solving engineering problems, yet the faculty were also teaching the courses to build the students capabilities in many other areas like communication, ethics, teamwork, and learning. The faculty may not have placed a large percentage toward the overall final grade in the class, but the courses were broader in scope than indicated by Table 1. After the 2019 notebook collection, the undergraduate curriculum committee reviewed all of the courses and proposed to redistribute the SO in order to ensure there are no more than two for each course for which data is collected and analyzed. Likewise, the designation of primary/secondary was removed. The two SO were the only ones for which data was to be collected and analyzed as part of the ABET continuous improvement process. The course can cover other SO, yet they would not be expected to collect data for these. As a result, most faculty streamlined the SO listed for each course to be only those expected for data collection and analysis.

Table 1 shows the distribution of SO after 2019. The goal was to have each required undergraduate class have no more than two SO. The instructor has the option to cover more than two, but the course was required to collect and analyze data to support only those that have been identified. If the faculty wishes to collect and analyze data for more, it will be accepted and used. By focusing on two, it is anticipated that the quality of the data will be improved without overly burdening the faculty.

Senior Design courses continue to cover as many SO as they have in the past, since the courses have played a significant role in ABET accreditation. The committee considered reducing the collection and analysis burden to only two SO for Senior Design courses, but this was not adopted since the data had been consistently collected and analyzed for many years and also contributes to the Universities participation in SACS accreditation as part of the Southern Association of Colleges and Schools Commission of Colleges. The instructors have a well documented system that was best to leave intact. It would be more of a disruption to reduce the collection and analysis of Senior Design data since it was so well established.

TABLE 1

DISTRIBUTION OF STUDENT OUTCOMES BEFORE 2016

\begin{tabular}{|l|l|l|l|l|l|l|l|l|l|l|l|l|}
\hline & \multicolumn{6}{|l|}{ Student Outcome (SO) } \\
\hline Course & $\mathrm{a}$ & $\mathrm{b}$ & $\mathrm{c}$ & $\mathrm{d}$ & $\mathrm{e}$ & $\mathrm{f}$ & $\mathrm{g}$ & $\mathrm{h}$ & $\mathrm{i}$ & $\mathrm{j}$ & $\mathrm{k}$ \\
\hline Engineering Analysis I & 1 & & & & 1 & & & & & & \\
\hline Statics & 1 & & & & 1 & & & & & & \\
\hline Dynamics & 1 & & & & 1 & & & & & & \\
\hline Eng. Graphics & 1 & & & & 1 & & & & & & \\
\hline Numerical Methods & 1 & & & & 2 & & & & 2 & & 2 \\
\hline Measurements \& Instrumentation & 1 & 1 & & & 1 & 2 & 2 & & 2 & 2 & 1 \\
\hline Materials and Lab & 1 & 1 & & 2 & 1 & 2 & 2 & & & & 1 \\
\hline Manufacturing Engineering & 1 & & 2 & 2 & 1 & & & 2 & 2 & & 2 \\
\hline Thermodynamics I & 1 & & & & 1 & & & & & 2 & \\
\hline Dynamics \& Controls & 1 & & & & 1 & & & & 1 & & 2 \\
\hline
\end{tabular}




\begin{tabular}{|l|l|l|l|l|l|l|l|l|l|l|l|}
\hline Fluid Mechanics & 1 & & & & 1 & & & & & & \\
\hline Mechanics of Solids & 1 & & 2 & & & 2 & & & & & 1 \\
\hline Machine Element Design & 1 & & 1 & & 1 & & 2 & 2 & & & 2 \\
\hline Thermodynamics II & 1 & & 2 & & 1 & & & 2 & & 2 & \\
\hline ME Lab & 1 & 1 & 2 & & 1 & & & & 1 & & 1 \\
\hline Heat Transfer & 1 & & 2 & & 1 & & & & & 2 & 2 \\
\hline Mechatronics & 1 & 2 & & 2 & 1 & 2 & 2 & & 2 & 2 & \\
\hline Sr. Design I & 1 & & 1 & 2 & 1 & 2 & 2 & 2 & 2 & 2 & 2 \\
\hline Sr. Design II & 1 & 2 & 1 & 2 & 1 & 2 & 2 & 2 & 2 & 2 & 2 \\
\hline
\end{tabular}

TABLE 2

DISTRIBUTION OF STUDENT OUTCOMES AFTER 2019

\begin{tabular}{|c|c|c|c|c|c|c|c|}
\hline & & at $C$ & cor & (SC & & & \\
\hline Course & 1 & 2 & 3 & 4 & 5 & 6 & 7 \\
\hline Engineering Analysis I & 1 & & & & & & \\
\hline Statics & 1 & & & & & & \\
\hline Dynamics & 1 & & & & & & \\
\hline Eng. Graphics & & & 3 & 4 & & & \\
\hline Numerical Methods & & & 3 & & & & 7 \\
\hline Measurements \& Instrumentation & & & & & 5 & 6 & \\
\hline Materials & 1 & & & 4 & & & \\
\hline Materials Lab & & & 3 & & & 6 & \\
\hline Manufacturing Engineering & & 2 & & 4 & & & \\
\hline Thermodynamics I & 1 & & & 4 & & & \\
\hline Dynamics \& Controls & & & 3 & & & & 7 \\
\hline Dynamics \& Controls Lab & & & 3 & & & 6 & \\
\hline Fluid Mechanics & 1 & & & 4 & & & \\
\hline Mechanics of Solids & 1 & & & 4 & & & \\
\hline Machine Element Design & & 2 & & 4 & & & \\
\hline Thermodynamics II & & 2 & & & & & 7 \\
\hline Thermal Fluid Lab & & & & & 5 & 6 & \\
\hline Heat Transfer & 1 & 2 & & & & & \\
\hline Mechatronics & & & & & 5 & & 7 \\
\hline Manufacturing Practices Lab & & & 3 & & & & \\
\hline Sr. Design I & 1 & 2 & 3 & 4 & 5 & & 7 \\
\hline Sr. Design II & 1 & 2 & 3 & 4 & 5 & 6 & 7 \\
\hline
\end{tabular}

\section{WORKSHOPS}

Before the beginning of a course-level collection and analysis cycle, the Department hosts an ABET Workshop that is mandatory for those teaching a course listed in Table 2. All other faculty are encouraged to attend. There are always a few faculty who are new to the department and new to the accreditation process. Experienced faculty also benefit from being reminded about the process and procedures used to assess $\mathrm{SO}$ and improve the program. At the end of the workshop, faculty are required to submit a plan for how each SO will be assessed that semester. The workshops are well attended because the Department Chair strongly encourages attendance. It has been observed that workshops are more effective when multiple faculty make brief presentations and there is active Q/A. The last workshop had seven different faculty address each of the seven SO individually, for 15-minutes followed by 15-minutes for Q/A. 
Table 3 shows a part of the assessment plan which is often described as a "mapping form" since it shows the course-level learning objectives and the ABET SO. The syllabus is integral to the SO assessment plan. It is recommended that each course have 5 to 10 course objectives. When a course has fewer than 5 or more than 10 course objectives, a subcommittee was tasked to review them and work with the faculty teaching the course. Likewise, when the mapping form shows all SO evaluated in all activities, then a subcommittee discusses this with the instructor since it is often unrealistic. For the SO, it has been found that 4 to 7 specific activities are a suitable number to collect and analyze data from the course. If an instructor proposes more than 7, a subcommittee will work with the instructor to streamline the process since the quality/analysis of the data often suffers when too much data is collected/analyzed. Likewise, if fewer than 4 activities are identified for the course SO, then the subcommittee works with the faculty to increase the number. This is often achieved by sharing ideas on how to construct, assign, collect, and analyze SO data which doesn't overly burden the faculty. Overall, it is better to have a strategic plan before the semester starts to do a good job collecting and analyzing a reasonable amount of data instead of a poor job of analyzing too little or too much data.

TABLE 3

\section{MAPPING OF ACTIVITY WITH COURSE OBJECTIVES AND STUDENT OUTCOMES}

\begin{tabular}{|c|c|c|c|c|c|c|c|c|c|c|c|c|c|}
\hline \multirow{2}{*}{ Activity } & \multicolumn{6}{|c|}{$\begin{array}{l}\text { Course Objective } \\
\text { (Documented in Notebook) }\end{array}$} & \multicolumn{7}{|c|}{$\begin{array}{l}\text { Student Outcome } \\
\text { (Documented in Notebook and Assessed) }\end{array}$} \\
\hline & 1 & 2 & 3 & 4 & 5 & 6 & SO1 & $\mathrm{SO} 2$ & SO3 & $\mathrm{SO} 4$ & SO5 & SO6 & SO7 \\
\hline Homework & & $\mathrm{x}$ & & $\mathrm{x}$ & & & & & & & & & \\
\hline IClicker & $\mathrm{x}$ & $\mathrm{x}$ & $\mathrm{x}$ & $\mathrm{x}$ & $\mathrm{x}$ & $\mathrm{x}$ & $\mathrm{x}$ & & & $\mathrm{x}$ & & & \\
\hline Quizzes & $\mathrm{x}$ & $\mathrm{x}$ & $\mathrm{x}$ & $\mathrm{x}$ & $\mathrm{x}$ & $\mathrm{x}$ & & & & & & & \\
\hline Exam 1 & $\mathrm{x}$ & $\mathrm{x}$ & $\mathrm{x}$ & & & & $\mathrm{x}$ & & & & & & \\
\hline Exam 2 & $\mathrm{x}$ & & & $\mathrm{x}$ & $\mathrm{x}$ & & $\mathrm{x}$ & & & & & & \\
\hline Exam 3 & & & & $\mathrm{x}$ & $\mathrm{x}$ & $\mathrm{x}$ & & & & & & & \\
\hline Final Exam & $\mathrm{x}$ & $\mathrm{x}$ & $\mathrm{x}$ & $\mathrm{x}$ & $\mathrm{x}$ & $\mathrm{x}$ & $\mathrm{x}$ & & & & & & \\
\hline Design Report & & & & & $\mathrm{x}$ & $\mathrm{x}$ & & & & $\mathrm{x}$ & & & \\
\hline
\end{tabular}

\section{Examples for SO}

Examples are shared for each SO on how to design, implement and assess activities for each SO. Workshops often provide an example of how the classroom student response system can be used to quickly collect and analyze data. The difficulty of the questions is not the focus nor that these may have little or no weight toward the student's final course grade. The focus is on the tools faculty may already be using in the class and how with attention to detail, relevant ABET SO data can be collected. Examples include iClicker quizzes, Blackboard quizzes, Gradescope for homework, Pearson Mastering for homework, or WileyPlus for homework. Many of these tools provide statistical analysis of student responses, which can be used to quantify SO assessment.

For SO1, tools that assess student work as either correct or incorrect are useful, yet for many of the other $\mathrm{SO}$ a rubric is best. Best practices are shared for exam, project and/or presentation rubrics. The key is to provide clear instructions to students about expectations for the assignment. When possible, faculty should give project report outlines with specific subheadings that align with expectations. These expectations should be aligned with the wording used by ABET for the particular SO. For example, SO2 covers engineering design and it is appropriate to suggest a more structured outline that might include the following: (1) Requirements, (2) Constraints, (3) Design Variables, (4) Multiple Solutions, (5) Analysis and Synthesis, (6) Trade-offs, and (7) Final Solution. Having a standard outline allows instructor to quickly see where consideration of multiple solutions (as an example) can be found. 
In almost all SO, a clear grading rubric can be generated with items following ABET's description, with rubric areas being: design constraints, design variables, alternative design consideration, iterative/creative decision-making process, analysis/synthesis, accessibility consideration, applicable codes/standards, constructability, functionality and cost analysis. Example rubrics are shared with faculty. Faculty are encouraged to share the grading rubric with students as well as the grade break-down for each part of the rubric. Not all team designs will cover all areas, so students should know it is acceptable to selfassess some as "not applicable". Yet again, if many areas are left blank or claimed to be "not applicable", then the students should know their work appears to be lacking. Having a detailed rubric aligned with ABET descriptions helps ease the burden of data collection and improves the overall quality of the assessment.

\section{CONCLUSION}

This paper summarizes how the ABET SO are distributed to all required engineering courses in the program. There continues to be heavy emphasis on senior design courses, but each course is expected to participate in the collection and analysis of SO for the continuous program improvement process. More faculty are aware of the process and understand the accreditation agency expectations. Workshops help guide faculty so good data is collected and analyzed showing relevant student work. The workshops often emphasize (1) knowing what is involved in each SO (2) planning before the semester begins on what data will be collected, (3) using available tools to reduce the data collection and analysis effort, (4) sharing detailed report templates, (5) sharing detailed grading rubrics, and (6) using words/phrases that align with ABET expectations. Instructors are encouraged to collect data early in the semester and not overly depend on data from the final exam or final report since there are limited opportunities to clarify or redo after the semester has ended. Overall more faculty are involved with program improvement and are knowledgeable about program accreditation.

\section{ACKNOWLEDGEMENT}

(C2021 American Society for Engineering Education. Gulf-Southwest Annual Conference Proceedings.

\section{REFERENCES}

ABET. (2021). Criteria for Accrediting Engineering Programs, 2020-2021. Retrieved April 30, 2021, from https://www.abet.org/accreditation/accreditation-criteria/criteria-for-accreditingengineering-programs-2020-2021/\#

Barr, R.E. (2013). Preparing for an ABET Accreditation Visit. ASEE-Gulf Southwest Section Annual Conference. Hosted by the University of Texas at Arlington, Arlington, TX.

Bern, C., Steward, B., Kaleita-Forbes, A., Mickelson, S., \& Brumm, T. (2005, June). Abet Is Coming! Getting Faculty Involved. Paper presented at 2005 Annual Conference, Portland, Oregon. doi: 10.18260/1-2-15498

James-Okeke, P.A., \& Ladeji-Osias, J.O., \& Scott, C J. (2019, June). ABET Accreditation: Best Practices for A Systematic Coordinated Multi-Program Approach. Paper presented at 2019 ASEE Annual Conference \& Exposition, Tampa, Florida. doi: 10.18260/1-2--32021

Karimi, A., \& Manteufel, R. (2020, July). Most Recent Updates to ABET-EAC-Criteria 3, 4 and 5. Paper presented at 2020 Gulf Southwest Section Conference [Online]. https://peer.asee.org/36008

Mak, F., \& Sundaram, R. (2016). Integrated Faculty Course Assessment Report (FCAR) Model with Traditional Rubric-Based (GR) Model to Enhance Automation of Student Outcomes Evaluation. 2016 IEEE Frontiers in Education Conference (FIE). doi: 10.1109/FIE.2016.7757342.

Manteufel, R.D., \& Karimi, A. (2016, June). Promoting Consistent Assessment of Student Learning Outcomes over Multiple Courses and Multiple Instructors in Continuous Program Improvement Paper presented at 2016 ASEE Annual Conference \& Exposition, New Orleans, Louisiana. doi: $10.18260 /$ p. 25986 
Miller, J. (2016). Minimizing Effort for ABET Student Outcomes Assessment while Maintaining Effective Results. Paper presented at 2016 International Conference on Computational Science and Computational Intelligence (CSCI). doi: 10.1109/CSCI.2016.0075

Pejcinovic, B. (2020). Design of Rubrics for Student Outcomes in 2019-2020 ABET Criteria. 43rd International Convention on Information, Communication and Electronic Technology (MIPRO), doi: 10.23919/MIPRO48935.2020.9245228

Peridier, V. (2020). A Faculty-Guided Continuous-Improvement Regimen with ABET Student-Outcome Scaffolding. Journal of Higher Education Theory and Practice, 20(14), 68-80.

Wear, L.L., Baiocchi, O.R., Alden, M., Gutmann, R., \& Sheng, J. (2012, June). Getting ABET Accreditation Right the First Time. Paper presented at 2012 ASEE Annual Conference \& Exposition, San Antonio, Texas. doi: 10.18260/1-2—21425 